Revista de Derecho YACHAQ

ISSN: 1817-597x (impresa) / ISSN: 2707-1197 (en linea)

Centro de Investigación de los Estudiantes de Derecho (CIED)

Universidad Nacional de San Antonio Abad del Cusco

N. ${ }^{\circ} 10-2019$

[pp. 21-38]

Fecha de recepción: 10/08/19

Fecha de aceptación:13/09/19

\title{
Compliance y regímenes sancionatorios de las personas jurídicas: algunas consideraciones económicas
}

\section{Compliance programs and sanctions regimes for legal entities: some economic considerations}

\author{
Diego Hernán Goldman[*]
}

\begin{abstract}
RESUMEN: La problemática de la responsabilidad penal o administrativa de las personas jurídicas y el estudio de los programas de compliance penal son cuestiones de creciente interés en la literatura jurídica hispanoamericana. El análisis de estos tópicos, sin embargo, es frecuentemente abordado desde una perspectiva dogmática que deja de lado el análisis de las implicancias materiales de estas herramientas jurídicas. En el presente trabajo, abordaremos el estudio de la responsabilidad de las personas jurídicas y del compliance penal atendiendo, particularmente, a sus efectos en aspectos tales como la disuasión de la criminalidad económi$\mathrm{ca}$, los procesos de toma de decisiones en las empresas, el nivel de actividad económica y el funcionamiento de los mercados de bienes y servicios. Para ello, recurriremos a las herramientas brindadas por disciplinas como el análisis económico del derecho y la teoría de juegos.
\end{abstract}

ABSTRACT: the problem of criminal or administrative liability from legal entities and the study of criminal compliance programs are issues of growing interest about the Spanish-American legal literature. The analysis of these topics, however, is frequently approached from a dogmatic perspective that neglects the analysis of the material implications from these legal tools. In this paper, we will address the study of the liability of legal entities and criminal compliance, having particular attention to their effects in aspects such as the deterrence of white collar crime, decision-making processes in companies, the level of economic activity and the functioning of the markets for goods and services. For this we will appeal to the tools provided by disciplines such as the law \& economics and game theory.

PALABRAS CLAVE: responsabilidad penal de las personas jurídicas, compliance penal, análisis económico del derecho.

KEYWORDS: criminal liability of corporations, criminal compliance, law \& economics.

[*] Abogado (Universidad de Buenos Aires). Magíster en Economía y Ciencias Políticas (ESEADE). Docente de postgrado de la Universidad de Palermo. Director general de Asuntos Jurídicos del Ministerio de Seguridad de la República Argentina.Contacto: goldman.diego@gmail.com 
I. INTRODUCCIÓN: COMPLIANCE Y RESPONSABILIDAD DE LAS PERSONAS JURÍDICAS, UN DÚO EN BOGA

La cuestión relativa a los sistemas de responsabilidad penal o administrativa de las personas jurídicas por los delitos vinculados a su actividad, si bien no es novedosa entre nosotros y registra antecedentes que se remontan al siglo $\mathrm{XIX}^{[1]}$, ha adquirido en los últimos años un renovado impulso en la región como consecuencia de los esfuerzos de organismos internacionales como la ONU y, en particular, la OCDE, por establecer estándares legislativos uniformes para la prevención y represión de delitos de carácter transnacional como el lavado de activos, la financiación del terrorismo y la corrupción.

Diversos instrumentos emanados de estos organismos, tales como la Convención de las $\mathrm{Na}$ ciones Unidas contra la Delincuencia Organizada Transnacional (Convención de Palermo) del año 2000, la Convención sobre la Lucha contra el Cohecho de Funcionarios Públicos Extranjeros en las Transacciones Comerciales Internacionales de la OCDE del año 1997 o el Convenio Internacional para la Represión de la Financiación del Terrorismo de la ONU del año 1999, prevén de hecho que los Estados parte incorporen a su legislación regímenes de sanciones civiles, administrativas o penales para las personas jurídicas. Esto ha motivado en los últimos años la sanción en Latinoamérica de diversas leyes destinadas a adaptar las legislaciones locales a estos estándares internacionales, máxime teniendo en cuenta que su incumplimiento constituye un serio impedimento para la integración de los países al flujo mundial del comercio y las finanzas. Así, por ejemplo, Chile sancionó en el 2009 la Ley N.을 20.393 de responsabilidad de las personas jurídicas por los delitos de lavado de activos, financiamiento del terrorismo y cohecho, mientras que Argentina hizo lo propio en el año 2017 mediante la sanción de la Ley N.을 27.401. Por su parte, en el año 2016, Perú sancionó la Ley $\mathrm{N}$.ㅇ 30.424 que establece un régimen de responsabilidad administrativa de las personas jurídicas por los mismos delitos.

Es decir, más allá de la discusión relativa a la naturaleza jurídica de las sanciones a las personas jurídicas -cuestión que no es del caso abordar aquí[2]_, lo cierto es que la legislación latinoamericana más reciente prevé la responsabilidad de los entes ideales por los delitos cometidos con su intervención, en su nombre o en su beneficio.

Ahora bien, esta responsabilidad de las personas jurídicas suele estar condicionada a dos circunstancias: 1) la comisión de un delito por parte de una persona humana, realizado en el marco de las actividades del ente ideal —el denominado «hecho de conexión», que opera de modo análogo a una

[1] Respecto de la cuestión en la historia legislativa argentina, se ha señalado que «[...] existen disposiciones legales que prevén sanciones o responsabilidades para aplicar a dichos entes, ya desde el siglo diecinueve. Tal es el caso de la Ordenanza de Ley de Aduanas aprobada por Ley 810 (1876), cuyo artículo 1027 consagraba la responsabilidad de los comerciantes por hechos de sus dependientes cuando se tratase de operaciones con la Aduana, y el artículo 1028, que establecía la posibilidad de imponer pena de multa a las personas jurídicas» (Prado, 2019, p. 81).

[2] En líneas generales, soy de la opinión de que las sanciones a las personas jurídicas revisten siempre naturaleza administrativa, aun cuando se las caracterice como «penales», dado que resultan incompatibles con las categorías dogmáticas del derecho penal y, lo que es más importante aún, con los principios constitucionales que lo rigen. En tal sentido, comparto la idea de que «[...] no resulta convincente ni adecuado el establecimiento de un sistema de responsabilidad «penal» de las personas jurídicas. Simplemente habría bastado con el sistema de consecuencias accesorias - de naturaleza administrativa - ya existente (aunque mejorable) para obtener los mismos resultados materiales (externamente idéntica clase de consecuencias) sin necesidad de trastocar la teoría de la imputación jurídico-penal del delito, según la cual, este se define como una acción u omisión típica — dolosa o imprudente-, antijurídica y culpable. Es completamente imposible hablar de acción, omisión, dolo, imprudencia o culpabilidad en las personas jurídicas, dado que estas categorías tienen un sentido psicológico por estar vinculadas hasta ahora únicamente con el ser humano» (Boldova Pasamar, 2013, p. 227). 
condición objetiva de punibilidad (Goldman, 2018a, pp. 438-439)-; y 2) la inexistencia o ineficacia de mecanismos internos de prevención, investigación y sanción de ilícitos por parte de la propia empresa -los programas de compliance-, que ha permitido o facilitado su consumación.

Dada la importancia que, como vemos, adquieren los programas de compliance dentro de los esquemas de responsabilidad de las personas jurídicas por hechos ilícitos, resulta oportuno hacer un paréntesis para definirlos sucintamente. Puntualmente, se los ha caracterizado señalándose lo siguiente:

[...] en el terreno jurídico-penal, la expresión compliance se emplea para designar única y exclusivamente la obligación de las personas jurídicas de establecer mecanismos internos que prevengan que determinadas personas físicas que ocupan puestos de relevancia dentro de ellas cometan un delito en beneficio de la empresa. De tal suerte, si esto último sucediera, no solo podría ser objeto de una sanción penal la persona física que cometió el delito, sino también la misma empresa, o sea, la unidad económico-social, integrada por elementos humanos, materiales y técnicos, que tiene el objetivo de obtener utilidades a través de su participación en el mercado de bienes y servicios. (Arocena \& Cesano, 2019, p. 56).

Los programas de compliance constituyen un elemento estructural de los regímenes sancionatorios de las personas jurídicas, en la medida en que su inexistencia o ineficacia resulta una condición esencial para la imposición de sanciones al ente ideal, cuando no el fundamento mismo de su responsabilidad. Desde el ángulo opuesto, la adopción de mecanismos efectivos de prevención, detección y sanción de delitos cometidos por sus miembros, es un factor que suele determinar la exención o atenuación de sanciones a la persona jurídica. Así, por ejemplo, en Argentina los artículos 8 y 9 de la $\mathrm{N}$. -27.401 prevén, respectivamente, la atenuación o exención de sanciones en virtud de la eficacia del denominado «programa de integridad» ${ }^{[3]}$. En el sistema chileno, en cambio, la falta de un adecuado sistema de compliance es el presupuesto mismo de la responsabilidad de la persona jurídica, y su adopción, una vez consumado el delito, pero antes de la realización del juicio, opera como circunstancia atenuante ${ }^{[4]}$. Finalmente, cabe mencionar que, en el régimen peruano de responsabilidad administrativa de las personas jurídicas, la adopción de un «modelo de prevención» con carácter previo a

[3] El artículo 8 de la Ley N. 27.401 prevé que se tengan en cuenta, al momento de graduar las sanciones a la persona jurídica, circunstancias tales como el incumplimiento de reglas y procedimientos internos, la omisión de vigilancia sobre la actividad de los autores y partícipes, y la denuncia espontánea a las autoridades como consecuencia de una actividad propia de detección o investigación interna. Por su parte, el artículo 9 prevé la exención de sanciones al ente ideal cuando concurran las siguientes circunstancias: «a) Espontáneamente haya denunciado un delito previsto en esta ley como consecuencia de una actividad propia de detección e investigación interna; b) Hubiere implementado un sistema de control y supervisión adecuado en los términos de los artículos 22 y 23 de esta ley, con anterioridad al hecho del proceso, cuya violación hubiera exigido un esfuerzo de los intervinientes en la comisión del delito; c) Hubiere devuelto el beneficio indebido obtenido».

[4] Según el artículo 3 de la Ley N. ㅇ. 20.393, las personas jurídicas serán responsables de los delitos que fueren cometidos directa e inmediatamente en su interés o para su provecho por sus dueños, controladores, responsables, ejecutivos principales, representantes o quienes realicen actividades de administración y supervisión, siempre que la comisión del delito fuere consecuencia del incumplimiento, por parte de esta, de los deberes de dirección y supervisión. A su vez, estos deberes de dirección y supervisión se considerarán cumplidos cuando «con anterioridad a la comisión del delito, la persona jurídica hubiere adoptado e implementado modelos de organización, administración y supervisión para prevenir delitos como el cometido». En relación a la graduación de sanciones, el artículo 6 contempla como circunstancia atenuante «la adopción por parte de la persona jurídica, antes del comienzo del juicio, de medidas eficaces para prevenir la reiteración de la misma clase de delitos objeto de la investigación». 
la comisión del delito por parte de la persona física exime de sanciones al ente ideal, mientras que su incorporación ex post, antes del juicio —de modo similar al de la legislación chilena-constituye una circunstancia atenuante ${ }^{[5]}$.

Efectuadas estas aclaraciones introductorias, no es mi intención aquí explayarme respecto de las implicancias dogmáticas de la irrupción del combo constituido por la responsabilidad de las personas jurídicas y los programas de compliance sobre las categorías y principios elementales del derecho penal. Tampoco adentrarme en los detalles del modo en que cada país ha legislado la cuestión. Ambas son cuestiones que han sido profusamente tratadas por la doctrina, y sobre las que no entiendo pertinente ahondar en esta oportunidad. Por el contrario, prefiero concentrar el esfuerzo sobre un asunto mucho menos transitado en la bibliografía en lengua castellana, pese a su evidente interés e importancia: los efectos materiales de los regímenes de sanciones a las personas jurídicas. Dicho en otras palabras, trataré aquí de analizar las consecuencias concretas que las nuevas normas acarrean en cuestiones tales como la disuasión de los delitos económicos, el impacto sobre la actividad y los costos de las empresas, y los efectos sobre la competencia y el funcionamiento de los mercados de bienes y servicios. Para acometer la tarea, echaré mano de las herramientas que nos brinda el análisis económico del derecho, que no es otra cosa que la aplicación del método de la economía - en particular, la microeconomía - al estudio de las normas e instituciones jurídicas, en nuestro caso del Derecho Penal o el Derecho Administrativo Sancionador.

Pasemos entonces, en primer lugar, a analizar qué efectos producen o pueden producir los sistemas de responsabilidad penal o administrativa de las personas jurídicas en materia de disuasión de delitos económicos.

\section{II. ¿LAS SANCIONES A LAS PERSONAS JU- RÍDICAS PREVIENEN LA CRIMINALIDAD ECONÓMICA?}

La primera pregunta relevante que deberíamos formularnos en relación a la adopción de los sistemas de responsabilidad penal o administrativa de las personas jurídicas es si estos, efectivamente, contribuyen a una reducción de los delitos vinculados a la actividad de las empresas, tales como el cohecho, el lavado de dinero, la evasión impositiva o los daños al medioambiente. Siendo una cuestión bastante obvia (ipara qué querríamos sancionar a las personas jurídicas, si ello no condujera en modo alguno a la reducción de la criminalidad vinculada a su actividad?), no pareciera; sin embargo, haber sido suficientemente abordada por la doctrina en nuestro medio, generalmente habituada a justificar las decisiones de política criminal más en razones axiológicas que pragmáticas ${ }^{[6]}$.

[5] Según el artículo 17 de la Ley N .o 30.424 (reformada por Decreto Legislativo N.o 1352), «la persona jurídica está exenta de responsabilidad por la comisión de los delitos comprendidos en el artículo 1, si adopta e implementa en su organización, con anterioridad a la comisión del delito, un modelo de prevención adecuado a su naturaleza, riesgos, necesidades y características, consistente en medidas de vigilancia y control idóneas para prevenir los delitos antes mencionados o para reducir significativamente el riesgo de su comisión». Por su parte, en el inciso d) del artículo 12 se contempla como circunstancia atenuante «la adopción e implementación por parte de la persona jurídica, después de la comisión del delito y antes del inicio del juicio oral, de un modelo de prevención».

[6] La justificación de la responsabilidad de las personas jurídicas por los delitos cometidos por sus miembros o dependientes - y la preferencia doctrinaria por los sistemas de responsabilidad «penal» y no administrativa - habitualmente descansa en argumentos tales como la necesidad de dar respuesta a demandas sociales frente a daños de gran magnitud derivados de la actividad empresarial, o el propósito de establecer cierta igualdad simbólica entre los autores de delitos comunes y de delitos «de cuello blanco». Así, se ha esgrimido como fundamentación de estos sistemas el hecho de que «[...] la propia sociedad ha dirigido su mirada crítica hacia los riesgos económicos, sobre todo los emergentes de las formas de producción, flujo financiero, ahorro y corrupción administrativa, posando su ponderación en los riesgos medioambientales, 
Una primera aproximación a la cuestión desde la óptica del análisis económico del derecho podría inclinarnos a afirmar que, en efecto, la imposición de sanciones a las personas jurídicas por los delitos cometidos por sus socios o dependientes debería tener un efecto disuasivo mayor al que tendría un sistema de responsabilidad penal individual enfocado exclusivamente en las personas físicas.

En este sentido, debemos recordar que la hipótesis fundamental del análisis económico del derecho penal consiste en sostener que los potenciales delincuentes actúan en forma racional, y que solo cometerán un delito en la medida en que el beneficio que esperan obtener de él resulte superior a los costos previstos de la acción, consistentes, principalmente, en la pena legalmente asignada al hecho, multiplicada por la posibilidad de que sea efectivamente aplicada. De tal modo, se ha sostenido que, de mantenerse constantes las demás variables, un incremento en la probabilidad de que el delincuente sea condenado, o un incremento en la magnitud del potencial castigo, conducirá, en mayor o menor medida, a la reducción del número de individuos dispuestos a cometer delitos (Becker, 1968, p. 176).

Desde esta perspectiva, la atribución de responsabilidad a las personas jurídicas podría tener un efecto disuasivo de la criminalidad económica en la medida en que incrementa el costo esperado de este tipo de delitos, al mejorar las posibilidades de que las sanciones sean efectivamente aplicadas. Al respecto, cabe recordar que una de las cuestiones sobre las que más se ha insistido a la hora de afirmar la insuficiencia de las herramientas tradicionales del Derecho Penal basado en la responsabilidad individual y en el axioma societas delinqueres non potest para afrontar la problemática de los delitos económicos, consiste en la dificultad para determinar y probar la participación criminal de cada sujeto en el marco de estructuras organizativas complejas, con responsabilidades fragmentadas y de naturaleza muchas veces transnacional. En este contexto, la imposición de sanciones al ente ideal sin necesidad de que se determine previamente la responsabilidad penal de los individuos que cometieron materialmente el delito -al resultar más sencilla puesto que permite soslayar cuestiones probatorias en ocasiones complejas-, fortalecería la percepción del costo esperado de esta clase de delitos.

\section{En resumen:}

[...] la posibilidad de asignar a las propias personas jurídicas responsabilidad por los delitos cometidos por sus directivos o dependientes en su nombre o representación -responsabilidad que, insisto, por su naturaleza debería ser ubicada dentro del ámbito del Derecho Administrativo sancionador- aparece como un modo de incrementar el costo esperado de esos actos ilícitos, al mejorar la probabilidad de que sean efectivamente sancionados y al disminuir los costos del procedimiento para las autoridades. (Goldman, 2018b, p. 18)

Por otra parte, la atribución de responsabilidad a las personas jurídicas puede generar incentivos para que sean las propias empresas las que establezcan mecanismos para prevenir, investigar, sancionar y denunciar los delitos cometidos en el marco de sus actividades, mediante la implementación de programas de compliance. Estos programas, cuando se encuentran adecuadamente diseñados y aplicados, pueden potenciar el efecto disuasivo respecto de los individuos proclives a cometer actos ilícitos en el contexto de sus funciones en la empresa, al facilitar la detección y sanción de esos desvíos, tanto en la órbita interna de la organización como en el ámbito penal, en la medida en que sean oportunamente denunciados a las autoridades -lo cual suele ser requisito para eximir de sanciones a la persona jurídica - y se pongan a su disposición

químicos y derivados de fallas en los procedimientos» (Yacobucci, 2017). Siguiendo esta línea, se ha enfatizado también el valor simbólico de la sanción penal a las personas jurídicas señalándose que «[...] nadie puede poner en tela de juicio que el sentido social de una pena no puede ser alcanzado de ninguna forma por alguna sanción administrativa» (García Cavero, 2010, p. 70). Sin embargo, más allá de alguna referencia vaga al efecto disuasivo de las sanciones a las personas jurídicas, es poco lo que se ha escrito en castellano para demostrar su real efectividad práctica. 
elementos de prueba que permitan su juzgamiento, de difícil obtención de otro modo.

Sin embargo, es de destacar que el efecto disuasivo de un esquema de responsabilidad penal o administrativa de las personas jurídicas dependerá en buena medida del modo en que esté diseñado el sistema y, muy particularmente, de los incentivos que genere para que las propias empresas se comprometan en la implementación de políticas efectivas de prevención de la criminalidad corporativa. Así, se ha señalado que, paradójicamente, un sistema de responsabilidad penal de las personas jurídicas mal diseñado podría llevar a un incremento de los delitos económicos:

Otra crítica contra la responsabilidad penal corporativa consiste en que podría aumentar efectivamente la cantidad de delitos corporativos. Si los esfuerzos corporativos por impedir la comisión de delitos por los empleados corporativos aumentan simultáneamente la probabilidad de que se descubran los delitos, y de que se persigan luego, la corporación podría optar por reducir sus esfuerzos preventivos. (Posner, 2007, pp. 673-674)

El supuesto al que refiere Posner, en el que la responsabilidad penal de las personas jurídicas podría constituir un incentivo para que estas disminuyan sus esfuerzos en materia de prevención de la criminalidad económica 0 , incluso, las lleven a obstaculizar las investigaciones por los delitos cometidos por sus empleados y directivos, se daría básicamente en un sistema que no contemple la existencia de programas adecuados de compliance y la cooperación con las autoridades como factores atenuantes o eximentes de la responsabilidad del ente ideal.

Siguiendo esta línea, se ha señalado también que, cuando las sanciones penales a la empresa puedan determinar su cierre, y en la medida en que los sistemas de prevención sean incapaces de eliminar totalmente el riesgo de que se cometan hechos ilícitos en el seno de la firma, se generarían incentivos para que el ente ideal disminuya los esfuerzos en monitorear y prevenir delitos (Hamdani \& Klement, 2008, pp. 275-276). Estos desincentivos a invertir en sistemas de disuasión eficaces serían, además, proporcionales al tamaño de la organización, toda vez que en la medida en que la cantidad de personal de la empresa crece, aumenta la probabilidad de que algún individuo cometa un delito, sin importar cuán grandes sean los esfuerzos preventivos de la firma (Hamdani \& Klement, 2008, p. 296).

El citado trabajo de Hamdani y Klement resulta sumamente interesante en este aspecto, en la medida en que analiza, recurriendo a herramientas conceptuales como la teoría de juegos, las razones por las cuales, bajo ciertos supuestos, la imposición de sanciones a las personas jurídicas podría tener efectos contraproducentes en términos de disuasión de los delitos económicos.

Así, los autores analizan el caso de las firmas profesionales - tales como los estudios jurídicos o de auditoría-, en las que los sujetos cuya conducta puede desencadenar la aplicación de sanciones penales a la empresa son, a su vez, socios de ella. En este supuesto, sanciones muy severas que puedan determinar la quiebra de la empresa por la comisión de un único hecho ilícito, podrían tener un efecto disuasivo menor que sanciones más leves. Para llegar a esa conclusión, los autores analizan el comportamiento estratégico de los socios: si cada uno de ellos supone que los otros pueden cometer actos ilícitos que lleven a la quiebra de la firma, sin importar su propia conducta apegada a las normas, se generan incentivos para el incumplimiento generalizado. Es que si un socio deberá afrontar la pérdida del valor de su participación en la empresa, aún actuando acorde a derecho, por el accionar ilícito de otro socio que no puede conocer ni evitar, le resultará racionalmente más conveniente cometer él mismo un acto ilícito, en la medida en que la ganancia obtenida resulte superior a la potencial pérdida en el valor de la participación en la sociedad, dada por el incremento en la posibilidad de que el delito sea detectado y sancionado por las autoridades. Resumidamente, a cada socio le resultará conveniente actuar ilícitamente si supone que los demás lo harán también, dado que al menos así reduciría las pérdidas que sufriría si la empresa igualmente quiebra como consecuencia de los actos de otro socio. El efecto disuasivo de la sanción a la persona jurídica, en este supuesto, será decreciente en la medida en que la probabilidad de que la infracción sea detectada se incremente (al aumentar el 
costo esperado del socio que no comete un delito) y que el tamaño de la organización sea mayor (al incrementarse la posibilidad de que se cometa un delito que desencadene una sanción, que el socio cumplidor no puede conocer ni evitar) (Hamdani \& Klement, 2008, pp. 282-287).

Dentro de este contexto, cabe sostener que los incentivos individuales de los socios o directivos de una persona jurídica para cometer delitos serán menores bajo un régimen en el que las sanciones al ente ideal son más acotadas y de carácter meramente monetario. En tal caso, el efecto disuasivo de la sanción se vería reforzado en la medida en que cada socio sepa que sus acciones individuales tendrán una mayor incidencia relativa en el costo esperado de las sanciones al ente ideal, al incrementar de modo más significativo tanto su monto total como la probabilidad de que sean aplicadas (Hamdani \& Klement, 2008, pp. 287-288). Al mismo tiempo, bajo un sistema de multas acumulativas, la posición relativa del socio que no delinque, cuando es probable que otro si lo haga, podría ser en general mejor que bajo un sistema en el cual la detección de un solo delito puede desembocar en el cierre de la empresa. Clarifiquemos esto con un ejemplo.

Supongamos una firma de auditoría con dos socios, cada uno de los cuales posee una participación de $\$ 1000$, y que la posibilidad de que un delito que determine su quiebra sea detectado y sancionado por las autoridades es del $10 \%$ por cada hecho que se cometa. Eso significa que cada socio, haga lo que haga, tendrá una pérdida esperada de $\$ 100$ si el otro socio comete un delito, del cual no obtiene ganancia alguna ( $\$ 1000$ de valor $\times 0,1$ de probabilidad $=\$ 100$ de pérdida esperada). Ahora bien, supongamos que, si ambos socios cometen actos ilícitos, la posibilidad de detección y sanción a la firma es del $20 \%$, pero el socio anteriormente «honesto» ahora puede obtener una ganancia de \$ 110 por su delito. Su pérdida esperada ahora es de $\$ 90$ ( $\$ 1000$ de valor $\times 0,2$ de probabilidad $=\$ 200$ de pérdida esperada «bruta» - $\$ 110$ de ganancia $=\$ 90$ de pérdida esperada «neta»), por lo cual es claro que, racionalmente, si su socio delinque, a él también le convendrá hacerlo.

Ahora, imaginemos un ejemplo similar, pero en el que cada hecho delictivo no determinará el cierre de la empresa, sino que recibirá una multa acumulativa que representará una pérdida de $\$ 500$ en el valor de la tenencia de cada socio. El socio que decide seguir actuando honestamente, afrontará en este caso una pérdida esperada de $\$ 50$ (\$500 de pérdida potencial $\times 0,1$ de probabilidad $=\$ 50$ ). En cambio, el socio que decida cometer un delito por el que espera obtener un beneficio de $\$ 110$, deberá saber que su accionar incrementará sus pérdidas esperadas a $\$ 90$ (\$1000 de pérdida potencial por acumulación de multas $\times 0,2$ de probabilidad $=$ $\$ 200$ de pérdida esperada «bruta» - \$110 de ganancia $=\$ 90$ de pérdida esperada «neta»). En definitiva, bajo un sistema de multas acumulativas, a diferencia de aquel en el que una única infracción lleva al cierre de la firma, al socio «honesto» le resultaría conveniente seguir siéndolo, en la medida en que cada nuevo delito multiplica las pérdidas potenciales. Además, en este caso, la incidencia de los actos de cada socio en el resultado total de la empresa es mucho mayor (en el primer ejemplo, la decisión de cometer una infracción duplica las pérdidas potenciales «brutas», que pasan de $\$ 100$ a $\$$ 200 , en tanto que en el segundo caso las cuadruplica, al pasar de $\$ 50$ a $\$ 200$ ), lo que debería hacer que cada individuo se sienta más responsable del resultado de sus propias decisiones, cuestión que puede representar un problema en organizaciones de cierta envergadura, en la que sus integrantes tienden a percibir que sus acciones individuales tienen escasa relevancia en el resultado colectivo.

De lo expuesto hasta aquí, se sigue que, para que un sistema de responsabilidad penal o administrativa de las personas jurídicas realmente contribuya a disminuir los delitos vinculados a la actividad empresarial, debe estar diseñado de modo tal que genere incentivos para que las empresas implementen programas eficaces de prevención del delito y, a la vez, para que los individuos que actúan en el marco de la organización se abstengan de llevar a cabo conductas ilícitas. Por el contrario, si el sistema de responsabilidad penal o administrativa de las personas jurídicas no logra alinear los incentivos de individuos y organizaciones en el sentido de que a los primeros les resulte conveniente evitar comportamientos ilícitos y a las segundas tratar de prevenirlos, es probable que la criminalidad económica se incremente en lugar de disminuir. 
Es, en este punto, donde la incorporación de los programas de compliance como factor eximente 0 atenuante de la responsabilidad de las personas jurídicas resulta fundamental para lograr esa convergencia de incentivos que tenga por efecto una reducción en los índices de criminalidad asociados a la actividad empresarial.

Como vimos, desde la perspectiva de la empresa, la inversión en prevención solo tiene sentido en la medida en que resulte menos costosa que el costo esperado en concepto de sanciones por delitos cometidos por sus directivos o dependientes y en la medida en que, además, contribuya a reducir este último. Siguiendo el razonamiento de Posner, no resultaría lógico que una organización invierta cuantiosos recursos en facilitarle el trabajo a las autoridades, para que luego estas impongan mayor cantidad de sanciones a la propia firma, a menos que el esfuerzo preventivo resulte tan eficaz que, por sí mismo, reduzca la posibilidad de que se cometan ilícitos al punto en que su costo esperado resulte menor al costo de implementar el programa de compliance. Sin embargo, aun cuando esto último pueda acontecer en algún caso, no resultaría incentivo suficiente para que una cantidad significativa de empresas haga un esfuerzo real por prevenir, detectar, sancionar y poner en conocimiento de las autoridades los delitos cometidos por su personal. Por ello, el modo más efectivo de lograr un compromiso real de las empresas en la prevención de la criminalidad económica, no puede ser otro que premiar ese esfuerzo mediante la reducción o eximición de sanciones o, lo que es lo mismo, asegurar que el costo de prevenir el delito sea menor al de permitirlo o tolerarlo. En tal sentido, resulta evidente lo siguiente:
[...] no basta con que la regulación legal recomiende, estimule e incluso disponga la conformación de un criminal compliance en la empresa, sino que deben darse, además, las condiciones para que tal conformación resulte económicamente atractiva para las empresas. Si la propia existencia o viabilidad económica de la empresa se contrapone finalmente a la lógica del cumplimiento normativo, queda claro que de nada servirá que la legislación promueva la conformación de este tipo de mecanismos empresariales. (Arocena \& Cesano, 2019, pp. 72-73)

En este punto, la mayoría de las legislaciones actuales prevén, precisamente, que la implementación, con carácter previo a la consumación del delito, de programas de compliance razonablemente eficaces, tenga un efecto eximente o atenuador de las sanciones a la persona jurídica. Así, como ya mencionamos anteriormente, la legislación chilena solo hace penalmente responsable a la persona jurídica por los delitos cometidos por sus directivos o representantes, cuando estos fueran consecuencia de la inexistencia o ineficacia de un adecuado modelo de prevención ${ }^{[7]}$ e, incluso, su adopción tardía opera como circunstancia atenuante ${ }^{[8]}$, lo que acontece también en la legislación peruana ${ }^{[9]}$, en la que la adopción de un programa de compliance con anterioridad a la comisión del delito es, además, considerado como un factor eximente de responsabilidad ${ }^{[10]}$.

Va de suyo que los incentivos para que las personas jurídicas adopten programas eficaces de prevención del delito perderán parte de su eficacia cuando la legislación condiciona la exención de sanciones al cumplimiento de requisitos de difícil constatación, como acontece en la legislación española ${ }^{[11]}$

[7] Ver artículo 3 de la Ley N. 20.393.

[8] Ver artículo 6, inciso 3), de la Ley N. 20.393.

[9] Ver artículo 17 de la Ley N. 30.424 (reformada por Decreto Legislativo N.o 1352).

[10] Ver artículo 12, inciso d), de la Ley N. 30.424 (reformada por Decreto Legislativo N. 1352).

[11] El artículo 31 bis del Código Penal español contempla un complejo sistema de exención de responsabilidad a la persona jurídica, cuyos requisitos varían según el delito que haya sido cometido por los representantes o directivos del ente ideal y en su nombre y beneficio; o bien por otras personas sin ejercer la representación de la persona jurídica, pero por su cuenta y en su beneficio, y en virtud del incumplimiento de los deberes 
y argentina ${ }^{[12]}$, o bien cuando, en la práctica, los jueces no tienen suficientemente en cuenta los esfuerzos de la empresa en materia de prevención como factor eximente de su responsabilidad. Esto último es lo que pareciera suceder, por caso, en los Estados Unidos, donde se ha cuestionado la tendencia de los jueces a sancionar a las organizaciones aún por hechos cometidos en exclusivo beneficio de sus autores, pese a que la legislación federal solo hace responsable a las corporaciones por actos cometidos con la intención de beneficiarlas (Hamdani \& Klement, 2008, p. 295), y se ha señalado que, en los diez primeros años de vigencia de las sentencing guidelines, solo en tres casos se tuvo en cuenta la existencia de un programa de compliance para graduar la sanción a la persona jurídica (Arocena \& Cesano, 2019, p. 119).

Otro aspecto para tener en cuenta al momento de analizar la eficacia de los incentivos legales, para que las personas jurídicas contribuyan a la prevención de la criminalidad económica mediante la implementación de programas de compliance, es la evaluación de sus costos y cómo ellos afectan a la actividad de la empresa. Sobre esta cuestión ahondaremos en párrafos venideros, pero cabe adelantar al respecto que, si la normativa exige a las empresas la implementación de sistemas de prevención demasiado onerosos, estas o bien no los implementarán, o bien disminuirán sus niveles de actividad o la reconducirán a mercados menos regulados, circunstancias en ambos casos socialmente disvaliosas.

Finalmente, y desde la perspectiva de los individuos que actúan a través de la persona jurídica o en el contexto de sus actividades, no resulta complejo observar el modo en que la implementación de un programa de compliance eficaz genera incentivos para evitar incurrir en conductas ilícitas. En este sentido, la existencia de mecanismos eficaces de prevención, detección, sanción y denuncia de ilícitos en el seno de la propia empresa incrementa los costos esperados del potencial infractor por dos vías. Por un lado, incrementa el costo esperado de la sanción penal, al mejorar las probabilidades de que se aplique una sanción, en la medida en que la colaboración de la persona jurídica con las autori-

de supervisión, vigilancia y control. En el primer supuesto, el ente ideal se exime de responsabilidad si se dan conjuntamente las siguientes circunstancias: «1. e el órgano de administración ha adoptado y ejecutado con eficacia, antes de la comisión del delito, modelos de organización y gestión que incluyen las medidas de vigilancia y control idóneas para prevenir delitos de la misma naturaleza o para reducir de forma significativa el riesgo de su comisión; 2. de prevención implantado ha sido confiada a un órgano de la persona jurídica con poderes autónomos de iniciativa y de control o que tenga encomendada legalmente la función de supervisar la eficacia de los controles internos de la persona jurídica; 3 . - los autores individuales han cometido el delito eludiendo fraudulentamente los modelos de organización y de prevención y $4 .{ }^{\text {a }}$ no se ha producido una omisión o un ejercicio insuficiente de sus funciones de supervisión, vigilancia y control por parte del órgano al que

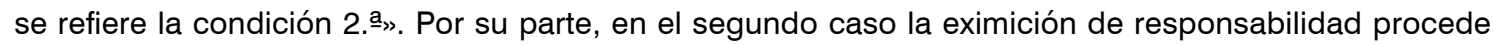
si «antes de la comisión del delito, ha adoptado y ejecutado eficazmente un modelo de organización y gestión que resulte adecuado para prevenir delitos de la naturaleza del que fue cometido o para reducir de forma significativa el riesgo de su comisión».

[12] El problema con el régimen de exención de sanciones de la Ley N. 27.401 pasa, fundamentalmente, por su defectuosa redacción, que exige —además de la implementación previa del denominado «programa de integridad» y la devolución del provecho del delito-, que la persona jurídica «espontáneamente haya denunciado un delito previsto en esta ley como consecuencia de una actividad propia de detección e investigación interna", sin que resulte claro si la norma refiere al mismo delito objeto del proceso - lo que implicaría exigirle a los entes ideales que establezcan sistemas de compliance capaces de detectar absolutamente todos los ilícitos cometidos en el contexto de su actividad, constituyendo una exigencia de imposible cumplimiento- o a otro delito - lo que lleva a preguntarse ¿qué sucede si no existe o no se ha detectado otro delito susceptible de ser denunciado?-. 
dades facilita la investigación y recolección de pruebas en un eventual proceso penal. Por otra parte, agrega a la sanción penal las sanciones de carácter disciplinario o laboral previstas en la normativa interna de la empresa, que por regla general son exigidas como parte integrante de los programas de compliance y que, en ocasiones, podrían resultar incluso más gravosas que las propias sanciones penales, en particular en el caso de quienes ocupan los cargos ejecutivos más altos y mejor remunerados.

En conclusión, para que un régimen de responsabilidad penal o administrativa de las personas jurídicas resulte efectivo en aras de disminuir la criminalidad asociada a la actividad empresarial, deberá estar diseñado de modo tal que resulte económicamente conveniente para las empresas comprometerse efectivamente en la prevención del delito. Para ello, deberán preverse incentivos adecuados para que a las organizaciones y los individuos les resulte beneficioso abstenerse de incurrir en conductas ilícitas, entre los que resulta elemental prever que la implementación de medidas efectivas de supervisión, control y sanción de los comportamientos desviados de los directivos y el personal de la firma, tengan un claro y concreto efecto atenuante o eximente de las sanciones penales o administrativas que pudieran corresponder a la persona jurídica. Al respecto, cabe tener en cuenta que un sistema de responsabilidad de las personas jurídicas mal concebido podría tener un efecto contrario al buscado, llevando a las empresas a convertirse en cómplices o encubridoras del delito. Por último, como veremos a continuación, un régimen de responsabilidad de las personas jurídicas bien diseñado no puede dejar de tener en cuenta el costo que la implementación de un adecuado programa de compliance tiene para las empresas, y los efectos que ese costo puede tener sobre su actividad, teniendo en cuenta aspectos tales como el tamaño de la firma y el tipo de mercados en los que opera.

\section{COMPLIANCE: UNA CUESTIÓN DE COSTOS}

En el apartado anterior vimos cómo, para que un sistema de responsabilidad penal o administrativa de las personas jurídicas resulte eficaz en el objetivo de contribuir a una reducción de la criminalidad económica, es preciso que genere incentivos para que las propias empresas adopten programas de compliance que permitan reducir el riesgo de que sus dependientes y directivos cometan actos ilícitos y que, en caso de que estos igualmente se produzcan, faciliten su investigación y sanción. En la medida en que, en el contexto del análisis de las actividades empresariales, la definición de esos incentivos puede reducirse a una cuestión de costo-beneficio, la primera conclusión que se deriva es la necesidad de que la implementación de esos programas de prevención les permita a las empresas reducir los costos esperados en concepto de sanciones. Ahora bien, como contrapartida, también, resulta necesario ponderar el costo que implica la implementación de un programa de compliance que cumpla las exigencias del ordenamiento jurídico, puesto que si esas erogaciones resultaran superiores al costo esperado de las sanciones derivadas de su inexistencia o insuficiencia, las organizaciones obtendrían un mayor beneficio decidiendo afrontar estas últimas en lugar de invertir en herramientas internas de prevención del delito.

Aunque parezca una obviedad, no son pocos los ejemplos de legislaciones que establecen estrictos requisitos a cumplir por las empresas en materia de compliance -imponiendo la obligación de adoptar costosos sistemas de auditoría, de recepción de denuncias, controles administrativos en el trato con clientes y proveedores, etcétera-, que no solo no atienden adecuadamente al tipo de riesgos que se busca prevenir, sino que tampoco diferencian entre empresas de diversa envergadura, pudiendo llegar a afectar sus operaciones, decisiones de inversión e, incluso, su participación en el mercado. Estos costos, además, suelen ser mayores en términos relativos para las empresas de menor tamaño, creando una ventaja competitiva a favor de las empresas más grandes, que puede constituir una auténtica barrera para el ingreso de nuevos competidores a ciertos mercados.

Un ejemplo respecto del efecto que los costos de implementación de los programas de integridad pueden tener en las empresas, y particularmente en aquellas de menor tamaño, lo podemos encontrar en diversos estudios realizados en los Estados Unidos con posterioridad a la sanción, en el año 2002, de la Ley Sarbanes-Oxley, que impuso a las sociedades que cotizan en bolsa estrictas reglas en ma- 
teria de controles internos, certificación de estados contables, composición de los comités de auditoría y entre otras normas de compliance destinadas a proteger a los inversores frente casos de fraude contable como los que involucraron, a entonces, importantes empresas como Enron o WorldCom. Así, analizado el efecto de las nuevas regulaciones sobre los costos de auditoría entre firmas que cotizaban en bolsa incluidas en los índices Standard \& Poor's, se observó un incremento del $141 \%$ entre los años 2003 y 2005 para las firmas más pequeñas, del 104 $\%$ para las medianas y del $62 \%$ para las de mayor tamaño. Estos costos de auditoría, además, tuvieron una incidencia muy disímil en los costos totales de empresas grandes y pequeñas, representando en el año 2004 un $0,13 \%$ de los ingresos de las primeras, y un 1,14 \% de los ingresos de las segundas (Kamar, Karaca-Mandic \& Talley, 2007, pp. 13-14).

La distinta incidencia que tiene el costo de los programas de compliance en la estructura de costos de empresas grandes y pequeñas puede explicarse en factores tales como la existencia de servicios con precio prácticamente fijo (honorarios de auditores y abogados que se establecen por hora trabajada), la posibilidad que tienen las firmas de mayor tamaño de aprovechar recursos humanos y materiales preexistentes o de obtener ventajas a partir de economías de escala. Se ha señalado, en este sentido, que «es mucho más fácil para las grandes empresas cumplir con la nueva legislación porque ellas ya operan bajo pautas bastante más estrictas o tienen más capital humano y financiero disponible para incorporar medidas de compliance» (Wilda, 2004, p. 681).

La creación de barreras artificiales de acceso a los mercados y de ventajas comparativas inequitativas a favor de las grandes empresas no es, sin embargo, el único motivo por el cual las legislaciones deberían distinguir según el tipo de empresa, actividad y clase de riesgos a prevenir a la hora de fijar requisitos para evaluar la eficacia de los programas de compliance o, incluso, para determinar los casos en los cuales las personas jurídicas deben ser susceptibles de responder penal o administrativamente por los delitos cometidos por sus dependientes. Existe, también, una cuestión de eficiencia en la asignación total de recursos destinados por el conjunto de la sociedad a la prevención de delitos que no puede ser soslayada.
Así, cabe también someter a un adecuado escrutinio en cada caso la idea de que trasladar a las empresas los costos de prevención de los delitos económicos resulta siempre una política criminal socialmente más eficiente, en virtud de lo oneroso y complicado que resultaría para las autoridades -bajo un esquema de estricta responsabilidad penal individual - investigar hechos y determinar autorías y grados de participación en el contexto de organizaciones complejas, estructuras societarias y financieras alambicadas, negocios transnacionales, etc. Estas premisas podrían no ser ciertas en todos los supuestos, y servir meramente de excusa no solo para imponer a las empresas costos difíciles de afrontar, sino también para relevar a las instituciones estatales de funciones que quizás podrían ejercer a un costo menor para el conjunto de la sociedad. En efecto, ¿cuál es la real dificultad que puede representar investigar un caso de cohecho o evasión fiscal en una pequeña empresa con tres o cuatro directores y menos de cincuenta empleados? ¿La justicia penal, en virtud de la economía de escala dada por contar con una dotación de recursos humanos y materiales especialmente dedicados a ello, no podría investigar esos casos a un costo mucho menor que el que representaría imponer a cada empresa la obligación de implementar un complejo programa de compliance? Supongamos que la implementación del programa de compliance obligara a las empresas a incorporar a un empleado adicional a su dotación -típicamente, el oficial de cumplimiento-, que hay mil empresas en el mercado, y que el $10 \%$ de ellas pudieran efectivamente verse involucradas en hechos de criminalidad económica. Eso implicaría que las empresas deberían pagar el sueldo de 1000 oficiales de cumplimiento para intentar disuadir 100 hechos delictivos. Agreguemos ahora que esos 100 casos, bien podrían ser investigados por un juzgado o fiscalía penal especializados, con una dotación de 50 empleados. ¿No resultaría socialmente mucho más eficiente que la prevención de delitos económicos fuera encomendada a 50 funcionarios judiciales altamente especializados y dotados de recursos, en lugar de a 1000 oficiales de cumplimiento repartidos en empresas cuya actividad principal, va de suyo, no es la prevención e investigación de hechos ilícitos? 
Recapitulando sobre lo expuesto, cabe señalar que, si bien es cierto que en determinadas circunstancias el establecimiento de la responsabilidad penal o administrativa de las personas jurídicas y la promoción de los programas de compliance puede resultar un modo socialmente eficaz de prevenir la criminalidad económica, no menos cierto es que la justificación a esa política criminal, generalmente, se focaliza en problemáticas circunscriptas básicamente a las grandes empresas. Al respecto, cabe traer a colación algunas reflexiones originadas en la sanción de la mencionada Ley Sarbanes-Oxley, pero que entiendo puede servir en general de advertencia respecto de los regímenes que venimos analizando:

La Ley no hizo distinciones entre las pequeñas empresas y las grandes corporaciones, que fueron en gran parte responsables de esta reforma radical. Muchos ejecutivos se quejan de que los costos adicionales de cumplir con la Ley están paralizando a las empresas más pequeñas y las están sacando del mercado. ¿Cuánta reforma corporativa está justificada? ¿En qué punto los costos superan a los beneficios? Parece que «la dosis correcta de medicina para Goliat casi puede matar a David». (Wilda, 2004, pp. 679-680)

Justo resulta señalar que, por lo general, las legislaciones más recientes en la materia efectúan distinciones entre los requisitos exigibles a los programas de compliance implementados por empresas grandes y pequeñas ${ }^{[13]} \mathrm{e}$, incluso, respecto del modo en que unas y otras responden por los delitos de sus directivos y empleados ${ }^{[14]}$. No obstante ello, esas distinciones, por lo general, están formuladas de modo sumamente vago y no establecen pautas lo suficientemente claras para tener por acreditados los requisitos mínimos exigibles a los programas de compliance en los distintos casos, lo que quedará librado en consecuencia a la apreciación discrecional de los jueces.

En definitiva, la legislación debería resultar lo suficientemente flexible como para que cada empresa pueda adoptar un programa de compliance que se adecue a sus particularidades, los riesgos concretos de su actividad y las características de cada mercado. Al mismo tiempo, debería brindar pautas suficientemente claras y objetivas para poder evaluar la efectividad de esos mecanismos de prevención y su aptitud para exonerar o atenuar la responsabilidad de la persona jurídica respecto de los delitos cometidos por sus directivos o dependientes, de modo tal que ello no quede sujeto completamente a la discrecionalidad judicial, con la consecuente inseguridad jurídica e incremento de costos en función de la necesidad de las empresas de adoptar preventivamente recaudos excesivos en materia de compliance.

Desde esta perspectiva, la efectividad de los programas de compliance debería evaluarse bajo una matriz que contemple aspectos como la envergadura de cada empresa, la complejidad de su organización o el hecho de que desarrolle operaciones en diversos países, pero también el tipo y magnitud de los riesgos concretos que se busca prevenir, las características de cada mercado y la necesidad de no dificultar, innecesariamente, la competencia. Siguiendo esta línea de ideas, he sostenido oportunamente lo siguiente:

[13] Por ejemplo, en Perú el artículo 17.2.1 de la Ley N.o 30.424 (reformada por Decreto Legislativo N. 1352) distingue entre las grandes empresas y aquellas clasificadas como micro, pequeñas y medianas a la hora de exigir la designación de un encargado de prevención autónomo, permitiendo que en el caso de las últimas dichas funciones puedan ser ejercidas por el órgano de administración de la sociedad. Del mismo modo, el Reglamento de dicha Ley aprobado por Decreto Supremo N ․o 2/2019 prevé en su artículo 44 que el modelo de prevención se adapte a las condiciones y características de las micro, pequeñas y medianas empresas. Similar solución respecto del ejercicio de las funciones de encargado de prevención u oficial de compliance es adoptada por el artículo 4, inciso 1), apartado b) de la Ley N. 020.393 chilena y el artículo 31 bis, inciso 3) del Código Penal español.

[14] En la legislación peruana, el artículo 7 de la Ley N ․o 30.424 (reformada por Decreto Legislativo N. 1352) establece las escalas de multas aplicables a las personas jurídicas en función de sus ingresos anuales. 
[...] no pueden aplicarse idénticos estándares al evaluar el compromiso con el cumplimiento normativo de una gran empresa multinacional con un organigrama altamente complejo, intrincados flujos financieros y gran disponibilidad de recursos, que el de una pequeña firma familiar con escaso giro comercial y decisiones concentradas en unas pocas personas. Va de suyo que, en este último caso, exigir cuestiones tales como la designación de un oficial de cumplimiento con autonomía del directorio, la implementación de un canal de denuncias anónimas o exhaustivas normas de conocimiento de socios comerciales, resultaría a la vez ruinoso para la empresa e innecesario para la prevención del tipo de delitos en que se puede ver involucrada. (Goldman, 2018b, p. 25)

Por último, los costos que el establecimiento de un régimen de responsabilidad penal o administrativa de las personas jurídicas y la exigencia de los programas de compliance imponen a las empresas adquieren también relevancia en el contexto del análisis del funcionamiento de la economía a un nivel más global, puesto que afectan el comportamiento de los actores en el mercado, condicionando sus decisiones en aspectos tales como el nivel de inversión, la investigación de nuevos productos o procesos, la contratación de personal o el trato con clientes y proveedores. Todo ello, a la postre, repercute en el nivel general de actividad, así como la conformación y grado de competencia de los mercados, cuestiones que analizaremos a continuación.

\section{EFECTOS SOBRE LA ACTIVIDAD, LOS MER- CADOS Y LA COMPETENCIA}

El modo en que cada legislación configura su modelo de responsabilidad penal o administrativa de las personas jurídicas y las exigencias que establece respecto de los programas de compliance que pueden o deben adoptar estas puede influir en los niveles de actividad económica y el funcionamiento de los mercados de distintas formas.

En primer lugar, debemos tener en cuenta que los procesos de toma de decisiones en las organizaciones están lógicamente influidos por el contexto institucional en el que se desenvuelven, que impone límites e incentivos para que sus órganos directivos adopten o no determinados cursos de acción. En este sentido, las decisiones de los individuos que actúan en el seno de las empresas se encuentran condicionadas tanto por el contexto institucional exógeno a la organización (v. gr. por la existencia de sanciones penales que pueden serles impuestas por determinados actos), como por el conjunto de reglas y procedimientos adoptado al interior del propio ente (v. gr. que impone el registro de ciertas actividades, su sometimiento a controles internos y a un régimen disciplinario propio), que a su vez se encuentra moldeado por el conjunto de normas exógenas que imponen obligaciones y responsabilidades a la persona jurídica. En efecto, esta interacción entre el contexto institucional - tanto exógeno como endógeno- - y las decisiones de los individuos que actúan dentro de las organizaciones, es el fundamento mismo de la existencia de los regímenes de responsabilidad penal o administrativa de las personas jurídicas y de los programas de compliance:

Este presupuesto, explicaría con solvencia en el ámbito jurídico-penal, la implementación de la responsabilidad penal de la persona jurídica en un modelo donde solo el individuo tiene capacidad para realizar una conducta delictiva (en un sistema de corte vicarial, en definitiva), pero donde existen constricciones, influencias y regulaciones interna que influyen cuando este es miembro de una organización. Y, ello vendría a fundamentar la propia existencia de los compliance programs: la conducta penalmente relevante es la que deviene de la decisión de la persona física, pero en la medida en que esta siempre toma en consideración el contexto social, es decir, la persona jurídica en la que se inserta, atribuir a esta consecuencias negativas derivadas de su forma de proceder condicionará su propia toma de decisiones (delictivas). Al mismo tiempo, al suponer constricciones a las que se someten las decisiones individuales, los compliances o modelos de organización y gestión resultan absolutamente necesarios para limitar o encauzar la capacidad de decisión del sujeto individual haciéndole desistir del comportamiento delictivo y fomentar conductas de cumplimiento normativo. (Aguilera Gordillo, 2018, pp. 227-228) 
Ningún problema, va de suyo, existe cuando esos condicionamientos a la toma de decisiones en la empresa tienen por efecto que sus órganos directivos se abstengan de incurrir en conductas ilícitas ni, mucho menos, cuando los llevan a adoptar eficaces sistemas de control interno tendientes a promover una cultura de apego a las normas. Ese, de hecho, es el propósito de los regímenes sancionatorios dirigidos a las personas jurídicas. Los inconvenientes surgen, sin embargo, cuando - por no estar bien calibradas las exigencias que la normativa impone a las organizaciones o no estar adecuadamente definido el tipo de riesgos que se procura prevenir - el exceso de rigurosidad del sistema impone costos excesivos a las empresas, torna engorrosos sus procedimientos internos o dificulta la toma de decisiones. Se corre el riesgo, así, de caer en auténticas «trampas disuasorias» en las que el temor a ser sujeto de sanciones coarte injustificadamente la cultura del emprendimiento, la investigación, el desarrollo de nuevos productos o de procesos innovadores (Aguilera Gordillo, 2018, p. 214). En esta línea, se han señalado los riesgos que entraña un régimen de responsabilidad de las personas jurídicas demasiado severo, toda vez que en tal contexto:

Los directivos tienden a ser conservadores con respecto a hacer nuevas inversiones e introducir nuevos productos porque las consecuencias de una decisión fallida podrían incluir demandas y sanciones penales. Desafortunadamente, este enfoque conservador de los negocios conducirá aún más a una economía lenta y un mercado laboral débil. (Wilda, 2004, p. 685)

Incluso, los condicionamientos impuestos por una normativa excesivamente rigurosa podrían no limitarse a moldear culturas corporativas innecesariamente conservadoras que atenten contra el dinamismo de la economía, sino incluso a inducir el abandono de ciertos mercados por parte de las empresas. Esto, que parece a priori una exageración, es, sin embargo, lo que aconteció en cierta medida con la sanción en los Estados Unidos de la Ley Sarbanes-Oxley, que condujo a un incremento del $26 \%$ en la cantidad de empresas que decidieron dejar de cotizar en bolsa (Wilda, 2004, p. 686). Por su parte, de una encuesta efectuada a 110 de las 236 empresas que dejaron de cotizar públicamente sus acciones entre los años 2001 y 2003, surge que el motivo más usual para adoptar esa decisión fue, precisamente, el elevado costo que implicaba cumplir con las regulaciones impuestas por la nueva legislación (Kamar, Karaca-Mandic \& Talley, 2007, p. 19).

Como se ve, la severidad del régimen de sanciones a las personas jurídicas y el costo que implica en cada sistema cumplir con los requisitos en materia de compliance pueden resultar factores que influyan no solo en el nivel de actividad de las empresas, sino también en la configuración y funcionamiento de los distintos mercados, al condicionar el número y características de las firmas que compiten en ellos. Estas cuestiones pueden ser analizadas en un esquema conceptual que tenga en cuenta las características del marco regulatorio, los costos de los programas de prevención, el nivel de riesgo de incurrir en conductas ilícitas inherente a cada actividad y la cultura organizacional de las empresas que compiten o pueden competir en el mercado (Goldman, 2018b, pp. 25-27).

Este análisis nos lleva a un esquema de ocho escenarios distintos, planteados en función de la combinación de los siguientes parámetros: a) la severidad del régimen de sanciones a las personas jurídicas, definida en función de la mayor o menor flexibilidad con la que la implementación de un programa de compliance sea considerada un factor atenuante o eximente de responsabilidad; b) el costo de implementación de los programas de compliance, ya sea que esté dado por las exigencias impuestas por el sistema legal o por las características propias de los riesgos que se procura prevenir; c) el mayor o menor riesgo de que los individuos vinculados a la empresa se vean involucrados en ilícitos penales, inherente a la actividad que la firma desarrolla; y d) el grado de compromiso de las empresas con el cumplimiento de sus obligaciones legales, dado por su alta o baja reputación.

En el primer escenario que se configura bajo este esquema, el programa de compliance no exime de responsabilidad a las empresas, implementarlo es costoso en relación a las ganancias esperadas, y el riesgo de incurrir en delitos vinculados a la actividad es alto. En este panorama hipotético, los incentivos para que las empresas comprometidas 
con el cumplimiento normativo participen del mercado es bajo - dado que el costo de los programas de compliance es alto y no contribuye a mitigar el alto riesgo de sufrir sanciones-, por lo que sería esperable un nivel de actividad bajo y una escasa cantidad de competidores, integrada básicamente por empresas de baja reputación. La conformación del mercado por empresas poco comprometidas con la prevención de ilícitos podría, además, potenciar el riesgo de que estos acontezcan. Resultaría aquí conveniente, para al menos reducir los niveles de riesgo, un régimen de responsabilidad de las personas jurídicas menos estricto, que atraiga a empresas de mejor reputación, con espaldas financieras lo suficientemente grandes como para afrontar los altos costos de prevención.

El segundo escenario es similar al descrito precedente, con la diferencia de que la actividad presenta menores riesgos de que se incurra en conductas criminales. Ello debería conducir a una mayor presencia de competidores, aunque sería esperable que entre ellos prevalezcan las empresas de baja reputación, que tendrían ventajas competitivas sobre las firmas que quisieran igualmente implementar costosos programas de prevención, de los que no obtendrían mayores ventajas. En el mediano plazo, el mercado quedaría circunscripto a empresas de baja reputación, lo que conllevaría un incremento de los niveles de riesgo, solo conjurable, nuevamente, mediante la flexibilización del régimen de responsabilidad de las personas jurídicas o de los requisitos exigidos a los programas de prevención, si su alto costo estuviera derivado principalmente de cuestiones normativas.

En el tercer escenario, si bien el programa de compliance en líneas generales no exime de responsabilidad a las empresas y el riesgo de incurrir en delitos es alto, los costos de implementar mecanismos eficaces de prevención son relativamente bajos. Tal circunstancia generaría ciertos incentivos para que empresas de alta reputación participen del mercado, en la medida de que la implementación de programas de compliance -aun cuando no resulten eficaces como factor eximente de responsabilidad- les permitiría competir con costos menores a través de la reducción del riesgo de sanciones. En este caso, el mercado, si bien acotado en la cantidad de competidores por su alto riesgo, mostraría una competencia entre empresas de baja y alta reputación, teniendo estas últimas cierta ventaja competitiva en la medida de que el costo del programa de compliance sumado al costo esperado de sanciones derivadas de hechos no evitables, resulte inferior al costo esperado de las sanciones por aquellas empresas que no adoptan ningún mecanismo de prevención. La preponderancia de las empresas de alta reputación, por otro lado, podría conducir a una reducción de los niveles de riesgo.

El cuarto escenario se caracteriza por la severidad del régimen de responsabilidad de las personas jurídicas -el programa de compliance sigue sin operar efectivamente como factor eximente de sanciones- pero a diferencia de los casos anteriores, tanto el riesgo de incurrir en conductas sancionables como el costo de implementar mecanismos eficaces de prevención es bajo. Aquí, tanto el nivel de actividad como el grado de competencia deberían resultar mayores - el costo esperado de sanciones no resultaría un factor limitante al ingreso de nuevos competidores-, pero las empresas de baja reputación podrían tener ventajas competitivas sobre las de mejor reputación, en la medida en que podrían ahorrar costos en materia de prevención de ilícitos sin que ello conduzca un incremento significativo del costo esperado en concepto de sanciones. De ser así, podría verificarse un paulatino incremento de los niveles de riesgo, provocado por la falta de adopción de medidas adecuadas de prevención.

Pasemos ahora a analizar los casos en los que la legislación acepta con mayor facilidad la eximición o atenuación de la responsabilidad de las personas jurídicas que hubieran adoptado programas eficaces de prevención de hechos ilícitos.

En el quinto escenario, las probabilidades de resultar involucrado en hechos ilícitos son altas, al igual que los costos de los programas de compliance. Sin embargo, como su adopción permite evitar la aplicación de sanciones, existen incentivos para que compitan al menos las empresas de alta reputación con recursos suficientes para afrontar los costos de los programas de prevención. En este mercado hipotético es esperable un nivel relativamente bajo de actividad y una competencia acotada a pocas empresas: firmas grandes de alta reputación y firmas grandes de baja reputación que puedan ab- 
sorber el costo de eventuales sanciones. Siempre y cuando las sanciones sean lo suficientemente altas como para que su costo esperado sea superior al de la implementación de un programa de compliance, las empresas de alta reputación tendrían una ventaja competitiva sobre las de baja reputación, en cuyo caso podrían ir disminuyendo los niveles de riesgo de la actividad.

El sexto escenario resulta similar a la anterior, con la diferencia de que el riesgo de la actividad es bajo, lo que eliminaría la barrera - constituida por el alto costo esperado de sanciones- para que empresas de baja reputación de menor tamaño ingresen a competir. Bajo estas condiciones, si bien los niveles esperados de actividad y competencia serían mayores, se diluirían las ventajas comparativas a favor de las empresas de mejor reputación, con el consecuente incremento de los niveles de riesgo, excepto que las sanciones a aquellas empresas que no adopten programas de integridad se eleven lo suficiente como para compensar la baja posibilidad de que sean aplicadas. Sin embargo, como este incremento en la intensidad de las sanciones desalentaría el ingreso al mercado de empresas más pequeñas, este escenario ilustra claramente la persistente disyuntiva entre mayores niveles de actividad y competencia o menores niveles de riesgo.

El séptimo escenario es aquel en que existen mayores incentivos para la adopción de programas de compliance verdaderamente eficaces, toda vez que está caracterizado por la existencia de un alto riesgo de sanciones y un bajo costo de prevención. Aquí no hay prácticamente posibilidad de obtener ventajas ahorrando costos en materia de prevención, dado que estos resultan bajos y en todo caso resultarían inferiores al riesgo potencial de recibir una sanción, que es elevado. Incluso, las empresas de baja reputación que no tuvieran un interés genuino en la prevención de riesgos tendrían un incentivo económico para adoptar un programa de prevención eficaz, salvo que el monto de las eventuales sanciones fuera tan bajo que no justificara los esfuerzos por evitarlas. En cuanto a la competencia, el alto riesgo inherente a la actividad no debería desalentar el ingreso de competidores al mercado ni determinar una reducción del nivel general de actividad, en la medida en que podría reducirse fácilmente y de modo económico.
Llegamos así al octavo y último escenario hipotético, en el cual la actividad presenta un bajo nivel de riesgo, la implementación de un adecuado programa de compliance no es costosa y, además, permite atenuar o eximir eventuales sanciones a la persona jurídica. No se presenta aquí ninguna circunstancia que afecte el potencial nivel de actividad ni la conformación de una competencia vigorosa entre empresas de distinto tamaño y reputación. Sin embargo, el bajo riesgo de ser pasibles de sanciones podría suponer una cierta ventaja competitiva a aquellas empresas de baja reputación dispuestas a obtener pequeños ahorros de la omisión de los mecanismos de control interno, que podría conjurarse incrementando la severidad de las sanciones. De lo contrario, podría generarse una situación propicia al aumento paulatino de los niveles de riesgo de la actividad.

Podemos apreciar, como corolario de lo expuesto en este apartado, que las características del régimen de responsabilidad penal o administrativa de las personas jurídicas y el costo que represente implementar un adecuado programa de compliance pueden resultar factores de relevancia tanto como condicionantes del comportamiento de las empresas -influyendo en el modo en que adoptan decisiones en cuestiones tales como la inversión en investigación y desarrollo de nuevos productos y procesos, el volumen de producción e, incluso, su continuidad-, como en la determinación de los niveles de actividad y el grado de competencia en el mercado.

Es importante destacar, además, que los efectos de un determinado diseño normativo dependerán de ciertas características intrínsecas a cada actividad, tales como el nivel de riesgo de que se produzcan hechos ilícitos y la mayor o menor dificultad para adoptar medidas eficaces de prevención. El hecho de que una misma norma pueda producir resultados muy diversos dependiendo del contexto en que sea aplicada debería conducir a revisar aquellos regímenes legales que adoptan idénticas reglas para todos los casos, sin distinguir entre las características de los distintos mercados y de los actores que operan en ellos. Del mismo modo, no debe perderse de vista que las herramientas legales deben estar al servicio de la política criminal, que será la que deberá establecer en cada caso concreto el interés a privilegiar: el nivel de riesgo socialmente tolerable, el incremento de la actividad 
económica o la promoción de la competencia. La preferencia por cada uno de estos factores puede variar en cada tipo de actividad económica. Pueden existir supuestos en los que sea preferible privilegiar la reducción de los niveles de riesgo por sobre el nivel de actividad y de competencia, por ejemplo, en actividades sumamente riesgosas como la minería o la generación de energía nuclear, mientras que en otros casos puede resultar tolerable un incremento en el riesgo de hechos ilícitos en aras de promover la competencia y una mayor actividad, por ejemplo, en la producción de alimentos de primera necesidad. En definitiva, lo relevante es tener en cuenta los incentivos que generan las normas, de modo que no se termine obteniendo resultados socialmente contraproducentes por el mero hecho de sumarse a una determinada tendencia legislativa en boga.

\section{CONCLUSIONES}

A modo de resumen de las cuestiones tratadas hasta aquí, podemos extraer algunas conclusiones en relación a los efectos materiales de los regímenes de responsabilidad penal o administrativa de las personas jurídicas por los hechos cometidos por sus directivos o dependientes en representación o beneficio de la empresa.

En primer lugar, podemos decir que la amenaza de sanciones a la persona jurídica puede constituir un incentivo eficaz para la disuasión de determinado tipo de delitos vinculados a la actividad de las empresas, socialmente más eficiente -en la medida que implica un empleo de recursos menor-que un esquema de responsabilidad penal estrictamente individual. Sin embargo, tal afirmación no resulta universalmente cierta y dependerá, en buena medi$\mathrm{da}$, de que el diseño del sistema genere incentivos para que las propias empresas inviertan recursos en la prevención, investigación y sanción del delito y para que a los individuos que actúan dentro de la organización les resulte conveniente abstenerse de incurrir en conductas ilícitas. En tal sentido, un régimen de responsabilidad de las personas jurídicas demasiado severo, que no brinde a las empresas la posibilidad de evitar sanciones demostrando su compromiso con la legalidad y su ánimo de colaborar con las autoridades, o que amenace con llevar a las firmas a la quiebra con demasiada facilidad, po- dría generar efectos contraproducentes, generando incentivos para que las organizaciones contribuyan a encubrir el delito y promoviendo una cultura de la transgresión normativa entre los individuos.

En segundo término, el diseño del sistema deberá ponderar si el costo de los programas de compliance exigidos a las empresas no resulta excesivo para estas, y si guarda relación con el tipo de riesgos que se busca prevenir. Una normativa que impone a las personas jurídicas obligaciones en materia de prevención de riesgos penales demasiado onerosas o difíciles de cumplir tenderá a perder su efectividad. En la medida en que la lógica de las decisiones empresariales es, por definición, la lógica del costo-beneficio, no tiene sentido que una organización con ánimo de lucro implemente programas de prevención tan onerosos que pongan en tela de juicio su viabilidad económica, o que aún sin llegar a ese extremo, no le reporten un beneficio apreciable en comparación al costo que le representaría afrontar el cumplimiento de sanciones penales o administrativas.

Por otra parte, y toda vez que un parámetro directriz de toda política criminal debiera ser la minimización de los costos de prevención del delito, cabrá tener en cuenta que no siempre responsabilizar a la persona jurídica es el modo socialmente más eficiente de disuadir la criminalidad económica. En efecto, existe una gran cantidad de ejemplos de delitos vinculados a pequeñas y medianas empresas, cuya investigación no ofrece mayores dificultades y puede realizarse, quizás economizando recursos, sin necesidad de despegarse de un estricto sistema de responsabilidad penal individual. Cabe preguntarse, entonces, si existe una efectiva necesidad de expandir los regímenes de responsabilidad penal de los entes ideales a un universo cada vez mayor de casos o si, por el contrario, estas herramientas legales debieran circunscribirse solo a los supuestos de organizaciones complejas que representan verdaderos obstáculos para la investigación de delitos como el lavado de activos, la evasión impositiva, los fraudes contables o los daños al medioambiente.

En tercer y último lugar, el análisis de los regímenes sancionatorios de las personas jurídicas y de los sistemas de compliance no puede perder de vista que estos influyen en las decisiones empresariales, repercutiendo sobre los niveles de actividad 
económica y la cantidad y calidad de los actores de los distintos mercados. La disuasión de la criminalidad económica, si bien es desde luego un objetivo socialmente relevante, no constituye un fin en sí mismo, que deba ser perseguido sin tomar en cuenta su repercusión sobre la producción de bienes y servicios o sobre el correcto funcionamiento de los mercados. Dependerá del tipo de actividad y de la clase de daños que se busque evitar, en cada caso, la ponderación de si resulta más importante prevenir el delito que promover la actividad económica y la libre competencia o si, por el contrario, resulta socialmente más beneficioso tolerar ciertos riesgos en aras de un mayor grado de prosperidad.

De lo que se trata, en definitiva, es de analizar las instituciones jurídicas desde una perspectiva pragmática, que haga hincapié en los efectos que las normas, generales o particulares, producen en la realidad, y no desde una aproximación dogmática aferrada a preconceptos y peticiones de principios.

\section{REFERENCIAS BIBLIOGRÁFICAS}

Aguilera Gordillo, R. (2018). Compliance penal. Régimen jurídico y fundamentación analítica de la responsabilidad penal de la persona jurídica y el compliance program (Tesis doctoral). Córdoba: Universidad de Córdoba.

Arocena, G. A. \& Cesano, J. D. (2019). Responsabilidad penal empresaria y «criminal compliance». Buenos Aires: Hammurabi.

Becker, G. (1968). Crime and punishment: an economic approach. Journal of Political Economy, vol. 76, N.ㅇ 2. University of Chicago, pp. 169-217.

Boldova Pasamar, M. A. (2013). La introducción de la responsabilidad penal de las personas jurídicas en la legislación española. Estudios Penales y Criminológicos, vol. XXXIII. Universidad de Santiago de Compostela, pp. 219-263.

García, P. (2010). La persona jurídica como sujeto penalmente responsable. En G. Yacobucci (dir.). Derecho penal empresario. Buenos Aires: B de F., pp. 61-88.

Goldman, D. H. (2018). Naturaleza jurídica y sentido económico de la responsabilidad «penal» de las personas jurídicas en Argentina. Reflexiones en relación a la Ley N.o 27.401. Revista de la Facultad de Derecho de México. Tomo LXVIII, N. 272 (septiembre-diciembre). Universidad Nacional Autónoma de México, pp. 423-455.

Goldman, D. H. (2018b). Bases para el análisis económico de los sistemas de compliance penal. lus et Veritas, N. 57 (diciembre de 2018). Pontificia Universidad Católica del Perú, pp. 14-28.

Hamdani, A. \& Klement, A. (2008). Corporate crime and deterrence. Stanford Law Review, vol. 61. Leland Stanford Junior University, pp. 271-310.

Kamar, E.; Karaca-Mandic, P. \& Talley, E. (2007). Sarbanes-Oxley effects on small firms: What is the evidence? USC CLEO Research Paper, N. C07-9. USC Law Legal Studies Paper, N.음 07-8. Harvard Law and Economics Discussion Paper, N. 588.

Posner, R. (2007). El análisis económico del Derecho. 2. ${ }^{a}$ ed. México: Fondo de Cultura Económica.

Prado, C. (2019). Cuestiones procesales de la imputación penal a las personas jurídicas, a propósito de la Ley 27.401. Cuadernos de Derecho Penal, N. 5 (mayo). Academia Nacional de Derecho y Ciencias Sociales de Córdoba, pp. 79-92.

Wilda, N. (2004). David pays for Goliath's mistakes: the costly effect Sarbanes-Oxley has on small companies. The John Marshall Law Review, vol. 38. The John Marshall Law School, pp. 671-692.

Yacobucci, G. (2017). La empresa como sujeto de imputación penal. La Ley, 27-11-2017, p. 1. 